\title{
Morphometric indicators for quality assessment in the aphid parasitoid, Lysiphlebus fabarum (Braconidae: Aphidiinae)
}

\author{
Mohammad AMERI ${ }^{1}$, Arash RASEKH $^{1 *}$, J.P. MICHAUD ${ }^{2}$ and Hossein ALLAHYARI ${ }^{3}$ \\ ${ }^{1}$ Department of Plant Protection, College of Agriculture, Shahid Chamran University of Ahvaz, Ahvaz, Iran \\ ${ }^{2}$ Kansas State University, Agricultural Research Center - Hays, 1232 240th Ave, Hays, KS 67601, USA \\ ${ }^{3}$ Department of Plant Protection, College of Agriculture, University of Tehran, Karaj, Iran
}

Key words. Braconidae, Aphidiinae, Lysiphlebus fabarum, Aphis fabae, body size, egg load, mass rearing, quality control

\begin{abstract}
Body size is a standard criterion of quality control in insect rearing and often assumed to correlate with fitness in parasitoid wasps, but various metrics of body size can be used. The purpose of this study was to determine which morphological feature provides the best correlation with body size and egg load in a thelytokous population of the parasitoid wasp, Lysiphlebus fabarum (Marshall), when reared on Aphis fabae Scopoli under standardized conditions in a growth chamber $\left(21 \pm 1{ }^{\circ} \mathrm{C}, 60-70 \% \mathrm{RH}\right.$, and $16 \mathrm{~L}: 8 \mathrm{D})$. Candidate metrics included head width, length and width of the pronotum, length and width of the right forewing, and length of the right hind tibia. In the first experiment, correlations were determined between these measurements and overall wasp body length. As head width and hind tibia length emerged as the most suitable proxies for total body length, the next experiment these two variables as proxies for egg load in females reared from different nymphal instars of the host aphid. There was a non-linear relationship between body size and egg load of wasps emerging from hosts parasitized in different nymphal instars. Egg load increased linearly with body size across all host growth stages, but the second nymphal instar was the most suitable stage for parasitism when speed of development was factored in. The results suggest that head width is a suitable morphometric for monitoring quality control in mass-reared cultures of this wasp.
\end{abstract}

\section{INTRODUCTION}

Lack of quality control procedures during the mass production of natural enemies may lead to failures in biological pest control (Calkins \& Ashley, 1989). Quality control guidelines have been established for about 30 beneficial species and are currently being developed for others (van Lenteren, 2003). The quality control criteria now used are based on laboratory observations that are easy to measure (e.g. emergence, sex ratio, lifespan, fecundity, adult size and predation/parasitism rate) (Calkins \& Ashley, 1989; Pavlik, 1993; Bourchier et al., 1993). Body size is one of the standard elements of quality control (van Lenteren et al., 2003), as it can have important effects on components of parasitoid fitness (i.e. mating success in males and egg load, egg size and longevity in females) (Godfray, 1994). Body size in massreared parasitoids also correlates with their field performance (van Lenteren et al., 2003).

Parasitoid size is determined by the total amount of nutritional resources available during larval development (Jervis et al., 2008). These nutritional resources vary as a function of host quality, which in turn depends on species (Harvey \& Vet, 1997; Sampaio et al., 2008), age or growth stage (Sequeira \& Mackauer, 1992a, b) and environmental conditions (Li \& Mills, 2004; Xu et al., 2008). In koinobiont parasitoids, the resource base is dynamic (hosts continue to feed and grow following parasitism) such that the growth potential of the host is a factor deter- mining its final quantity (Nicol \& Mackauer, 1999). When host resources are limiting, parasitoids face trade offs in resource allocation to different biological traits such as egg load, wing muscles, etc. that tend to unfold in a species-specific manner during development (Jervis et al., 2008). Consequently the best morphological indicators of parasitoid fitness probably vary among species.

Different proxies have been used to estimate body size, including dry or wet body mass (Sequeira \& Mackauer, $1992 a, b)$ and length measurements such as hind tibia length (Li \& Mills, 2004) and head capsule width (O’Neill \& Skinner, 1990). Among these measurements, hind tibia length is perhaps the most commonly used (Godfray, 1994) but is possibly not the most reliable indicator of overall body size (Nicol \& Mackauer, 1999). Moreover, the use of different morphological characters as proxies of body size can result in different estimates of size variation within populations and even lead to erroneous conclusions (Gauld \& Fitton, 1987; Hurlbutt, 1987; Nicol \& Mackauer, 1999). As the estimation of body volume from linear measurements is not always straightforward, body mass may be the most reliable proxy of body size (Sequeira \& Mackauer, 1992a, b; Harvey et al., 1994, 2000; Harvey \& Strand, 2002). For example, van Alphen \& Thunnissen (1983) reported that females of Pachycrepoideus vindemiae Rondani (Pteromalidae) had greater dry mass than males of the same head width. Also, measurements of body mass often reveal much greater variation than linear measurements (Harvey et al., 2000)

\footnotetext{
* Corresponding author; e-mail: arashrasekh@gmail.com
} 
because mass scales approximately with the cube of length. However, some traits in female parasitoids, like the ability to capture and subdue a host, may vary with body length (Price, 1972; Gerling et al., 1990) or ovipositor length (Brandl \& Vidal, 1987) rather than body volume.

This paper reports the results of experiments that were designed to assess the relative utility of various morphological measurements as predictors of body size and egg load, as well as the relative suitability of different host growth stages, in Lysiphlebus fabarum (Marshall) (Hymenoptera: Aphidiinae), a solitary koinobiont parasitoid that commonly parasitizes Aphis fabae Scopoli in Iran (Rakhshani et al., 2006; Talebi et al., 2009). The objective was to generate results that would be useful for monitoring quality control in mass cultures of this species and improving the performance of material released in the field.

\section{MATERIAL AND METHODS}

\section{Insect colonies}

A stock colony of black bean aphid, A. fabae, was established from material taken from bean fields in the Zanjan Province in spring, 2011, and mummies of the parasitoid Lysiphlebius fabarum were obtained from the same samples. Tests confirmed thelytokous reproduction in this population (Rasekh et al., 2011). The stock colony of $A$. fabae was maintained on potted broad bean, Vicia fabae, grown in pots filled with fertilized sawdust and the parasitoid colony was maintained on this aphid colony. All insects and experiments were maintained under the same conditions in growth chambers at $21 \pm 1^{\circ} \mathrm{C}$, $65-75 \% \mathrm{RH}$, and a $16 \mathrm{~L}: 8 \mathrm{D}$ photoperiod.

\section{Correlation of morphometrics with body length}

In the first experiment, a total of 215 mummies were selected randomly from the stock colony and the adult females collected upon emergence. Various morphological characters were measured on each wasp to within an accuracy of $0.01 \mathrm{~mm}$ under a stereo microscope equipped with an ocular micrometer. They included total body length from the top of head to the tip of abdomen (Fig. 1A), head width, pronotum length and width, right front wing length and width and right hind tibia length (Fig. 1B-G). Linear regression was used to evaluate their utility as predictors of total body length.

\section{Correlation of morphometrics with egg load}

In the second experiment, synchronous cohorts of black bean aphid were established on seedlings of bean plant in ventilated plastic cylinders $(8 \mathrm{~cm} \times 15 \mathrm{~cm})$ by allowing adult $A$. fabae to deposit nymphs on the plants for $12 \mathrm{~h}$ and then removing them. Then, three day-old L. fabarum females without prior experience with aphids were introduced to each aphid cohort in a $1: 5$ ratio ( 1 wasp for each 5 aphids). After $6 \mathrm{~h}$, the wasps were removed and the parasitized aphids were reared until wasp emergence.

Development of the parasitoid in a range of host life stages was assayed. Based on preliminary observations under these conditions, nymphal instars of $A$. fabae were $1,2.25,3.75,5.75$ and 7.75 days old for $1^{\text {st }}, 2^{\text {nd }}, 3^{\text {rd }}, 4^{\text {th }}$ and adult, respectively, and wasps were introduced to different aphid cohorts on these time frames. Wasps emerging from the different host cohorts were kept in groups of five in ventilated plastic cylinders $(8.0 \mathrm{~cm} \times$ $15.0 \mathrm{~cm}$ ) and provisioned with droplets of diluted honey on a strip of wax paper and water on a cotton ball. The water was

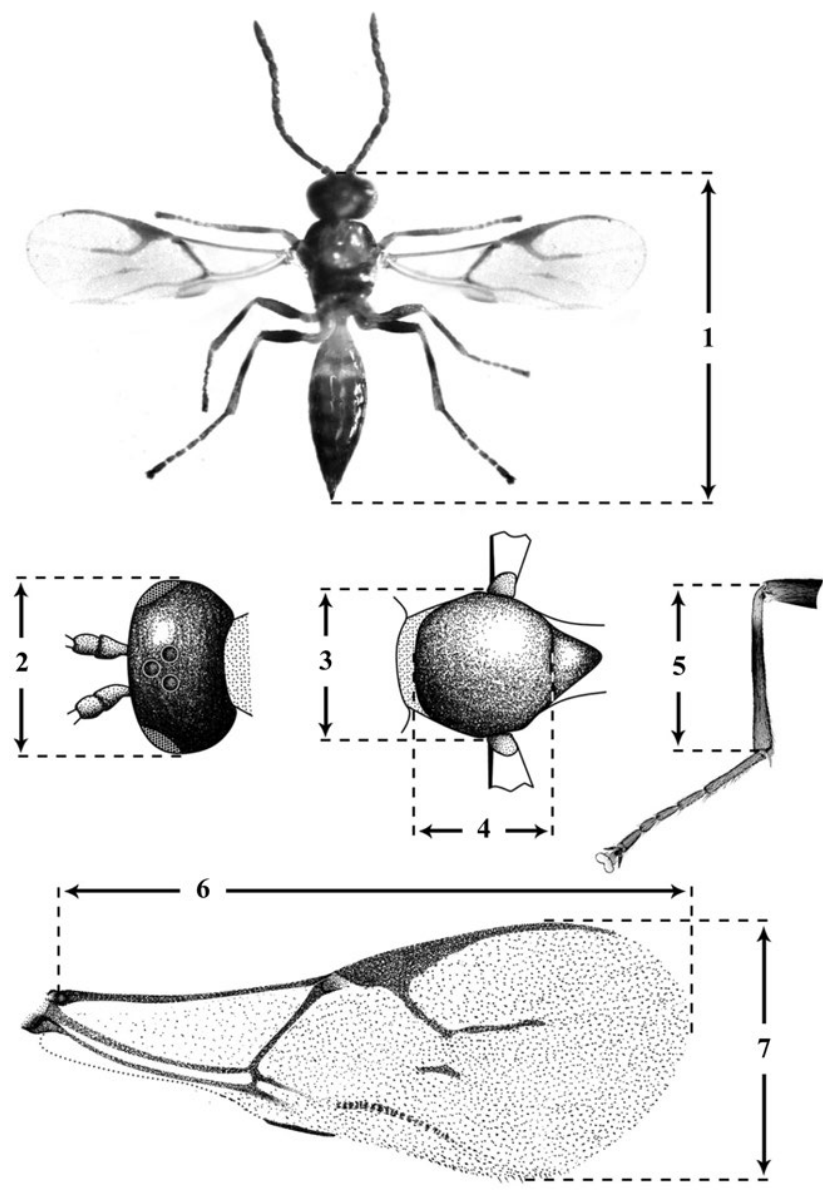

Fig. 1. Categories of morphological measurements made on adult Lysiphlebus fabarum. 1 - body length; 2 - head width; 3 pronotum width; 4 - pronotum length; 5 - hind tibia length; 6 wing length; 7 - wing width.

refreshed daily and the diluted honey was refreshed every second day.

At three days post-emergence, wasps were killed by exposure to alcohol vapor for three minutes. Since head width and hind tibia length emerged as the best predictors of body size in the first experiment, these were measured in each wasp. Subsequently, each wasp was dissected on a glass slide in saline solution $\left(7.5 \mathrm{~g} \mathrm{NaCl}^{-1}\right)$ under a stereo microscope equipped with a digital camera (Nikon Coolpix S10, Nikon Corporation, Tokyo, Japan). Both left and right lobes of the ovaries were photographed separately and resolution was enhanced with digital software (Adobe Photoshop CS5, Adobe Corporation, San Jose, CA, USA) so that eggs could be accurately counted.

\section{Statistical analysis}

Regression was used to test relationships between the different morphological characters and body length and the best predictor was inferred to be that yielding the highest value of $\mathrm{R}^{2}$. To determine best fit, five types of model were fit to the data: linear $(\mathrm{y}=a x+b)$, quadratic $\left(\mathrm{y}=a x^{2}+b x+c\right)$, power $(\mathrm{y}$ $\left.=a x^{b}\right)$, exponential $\left(\mathrm{y}=a e^{b x}\right)$ and $\operatorname{logarithmic}(\mathrm{y}=a \cdot \ln (x)+b)$. The corrected Akaike information criterion (AICc) was used for model comparison. Models with lower AICc values are better descriptors of the relationship between variables, and models differing by less than 2 are considered to be indistinguishable from each other (Burnham \& Anderson, 2002). The $\mathrm{R}^{2}$ value was used to select best model when 2 or more models had a similar AICc criterion. Treatments were compared by one-way 


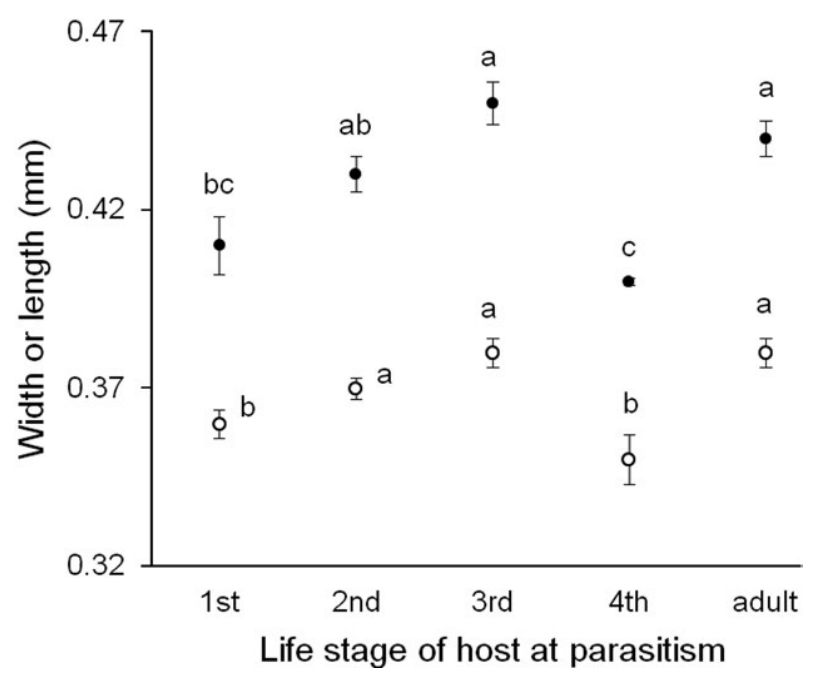

Fig. 2. Mean \pm SE head width (open circles) and hind tibia length (closed circles) for Lysiphlebus fabarum females emerging from aphid hosts parasitized in different life stages. Means bearing the same letter were not significantly different from each other (LSD, $\mathrm{P}>0.05$ ).

ANOVA and means separated by Fisher's protected LSD test (SPSS, 1998).

\section{RESULTS}

Wing length yielded the highest correlation with total body length, followed by head width, pronotum width, hind tibia length, wing width and pronotum length (Table 1). However, the procedures for measurement of wing length are difficult and give rise to potential sources of error (the wings are very transparent and must first be detached from the thorax). Similarly, since the pronotum presented an irregular three-dimensional shape that was not well suited for obtaining consistent linear measurements, head width and hind tibia length were selected for subsequent correlational analysis with egg load.

Wasps reared from aphids parasitized at different growth stages exhibited significant differences in head width $(\mathrm{F}=7.68 ; \mathrm{df}=4,102 ; P<0.001)$ and hind tibia length $(\mathrm{F}=5.14 ; \mathrm{df}=4,102 ; P<0.001$; Fig. 2). Since right and left ovaries did not differ in the number of eggs they contained $(\mathrm{F}=0.32 ; \mathrm{df}=1,195 ; P=0.560)$, the total number of eggs in both ovaries was analyzed. Total number of eggs in ovaries varied significantly with host

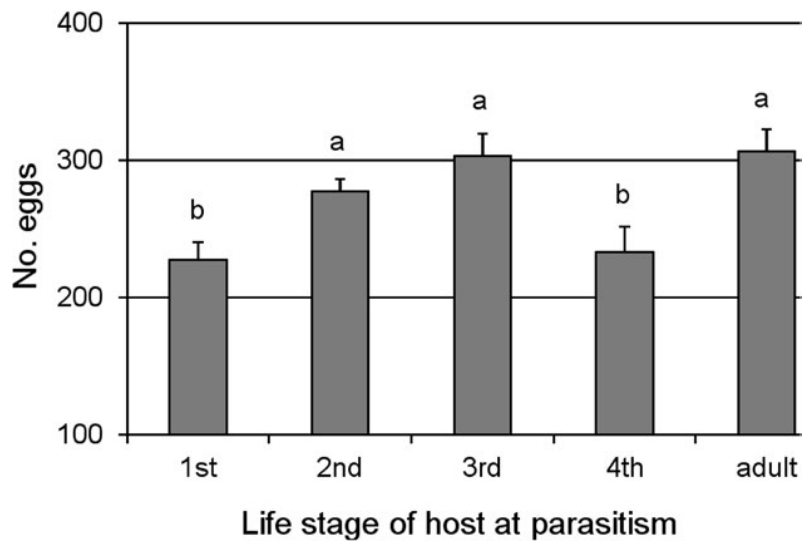

Fig. 3. Mean + SE egg loads of female Lysiphlebus fabarum emerging from aphid hosts parasitized in different life stages. Means bearing the same letter were not significantly different from each other (LSD, P > 0.05).

stage at time of parasitism $(\mathrm{F}=6.32 ; \mathrm{df}=4,98 ; P<$ $0.001)$, the most being observed in wasps emerging from aphids parasitized in the third instar or adult stage (Fig. 3). The relationships between egg load and head width or egg load and hind tibia length were best described by a quadratic model in 6 out of 10 cases, a power function in 3 out of 10 cases, and a linear equation in one case (Table 2). A quadratic model was the best fit for second instars, the most suitable and preferred host growth stage for mass rearing of the parasitoid. However, the nature of these relationships varied depending on the host stage at time of parasitism (Table 3 and Fig. 4). Since head width was more congruent with egg load in terms of mean separation among life stages at time of parasitism (compare Figs 2 and 3) and in most cases yielded a lower value of AICc compared to hind tibia length, especially in second instars, head width may serve as a better predictor of egg load than hind tibia length.

\section{DISCUSSION}

Body size and dry mass are metrics most often used to predict parasitoid fitness (Roitberg, 2001). Although body mass has been viewed as a reliable proxy of body size, some studies have shown that body length or ovipositor length relative to host size are important factors determining the outcome of parasitoid-host interactions (Price, 1972; Brandl \& Vidal, 1987; Gerling \& Mackauer, 1990).

TABLE 1. Linear measurements of various body parts of Lysiphlebus fabarum and their correlations with total body length $(n=$ 215). The regression equation employs the morphological parameter as the explanatory variable for body length.

\begin{tabular}{|c|c|c|c|c|c|c|c|}
\hline \multirow{2}{*}{ Morphological parameter } & \multirow{2}{*}{ Mean $\pm \mathrm{SE}$} & \multicolumn{2}{|c|}{ Regression equation } & \multirow{2}{*}{$\mathrm{R}^{2}$} & \multirow{2}{*}{$\mathrm{df}$} & \multirow{2}{*}{$\mathrm{F}$} & \multirow{2}{*}{$P$} \\
\hline & & Slope & Intercept & & & & \\
\hline Body length & $1.58 \pm 0.008$ & - & - & - & & & \\
\hline Head width & $0.37 \pm 0.001$ & $3.93 \pm 0.172$ & 0.124 & 0.71 & 1,213 & 523.1 & $<0.001$ \\
\hline Pronotum length & $0.27 \pm 0.001$ & $3.80 \pm 0.195$ & 0.537 & 0.64 & 1,213 & 380.0 & $<0.001$ \\
\hline Pronotum width & $0.29 \pm 0.001$ & $3.45 \pm 0.157$ & 0.555 & 0.70 & 1,213 & 486.0 & $<0.001$ \\
\hline Wing length & $1.31 \pm 0.006$ & $1.07 \pm 0.038$ & 0.174 & 0.79 & 1,213 & 788.7 & $<0.001$ \\
\hline Wing width & $0.51 \pm 0.002$ & $2.16 \pm 0.112$ & 0.470 & 0.63 & 1,213 & 369.7 & $<0.001$ \\
\hline Hind tibia length & $0.42 \pm 0.002$ & $2.61 \pm 0.121$ & 0.478 & 0.69 & 1,213 & 469.5 & $<0.001$ \\
\hline
\end{tabular}


TABLE 2. AICc and $\mathrm{R}^{2}$ values for different models describing the dependence of egg load on head width and hind tibia length for Lysiphlebus fabarum females emerging from aphid hosts parasitized at different life stages.

\begin{tabular}{|c|c|c|c|c|c|}
\hline \multirow{2}{*}{ Stage } & \multirow{2}{*}{ Model } & \multicolumn{2}{|c|}{ Head width } & \multicolumn{2}{|c|}{ Hind tibia length } \\
\hline & & $\mathrm{R}^{2}$ & $\mathrm{AICc}$ & $\mathrm{R}^{2}$ & $\mathrm{AICc}$ \\
\hline \multirow{5}{*}{$1^{\text {st }}$ Instar } & Linear & 0.40 & 145.7 & 0.70 & 132.9 \\
\hline & Quadratic & 0.41 & 148.5 & 0.74 & 132.5 \\
\hline & Power & 0.43 & 145.8 & 0.71 & 134.0 \\
\hline & Exponential & 0.42 & 145.7 & 0.72 & 132.9 \\
\hline & Logarithmic & 0.40 & 145.8 & 0.67 & 134.0 \\
\hline \multirow{5}{*}{ 2nd Instar } & Linear & 0.14 & 182.2 & 0.31 & 177.0 \\
\hline & Quadratic & 0.45 & 118.8 & 0.38 & 177.2 \\
\hline & Power & 0.14 & 181.9 & 0.30 & 176.6 \\
\hline & Exponential & 0.13 & 182.3 & 0.29 & 177.0 \\
\hline & Logarithmic & 0.15 & 197.7 & 0.32 & 176.6 \\
\hline \multirow{5}{*}{ 3rd Instar } & Linear & 0.50 & 204.7 & 0.43 & 208.1 \\
\hline & Quadratic & 0.50 & 207.3 & 0.44 & 210.4 \\
\hline & Power & 0.53 & 204.7 & 0.47 & 207.9 \\
\hline & Exponential & 0.52 & 204.7 & 0.46 & 208.1 \\
\hline & Logarithmic & 0.50 & 204.7 & 0.44 & 207.9 \\
\hline \multirow{5}{*}{ 4th Instar } & Linear & 0.74 & 119.5 & 0.76 & 118.7 \\
\hline & Quadratic & 0.75 & 122.2 & 0.77 & 120.6 \\
\hline & Power & 0.69 & 119.9 & 0.72 & 119.7 \\
\hline & Exponential & 0.69 & 119.5 & 0.72 & 118.7 \\
\hline & Logarithmic & 0.74 & 119.9 & 0.74 & 119.7 \\
\hline \multirow{5}{*}{ Adult aphid } & Linear & 0.25 & 160.4 & 0.23 & 160.8 \\
\hline & Quadratic & 0.53 & 154.3 & 0.27 & 162.7 \\
\hline & Power & 0.22 & 159.8 & 0.15 & 160.9 \\
\hline & Exponential & 0.20 & 160.4 & 0.15 & 160.8 \\
\hline & Logarithmic & 0.27 & 159.8 & 0.22 & 160.9 \\
\hline
\end{tabular}

TABLE 3. Quadratic regressions of egg load on head width and hind tibia length for Lysiphlebus fabarum females emerging from aphid hosts parasitized at different life stages. $P$ values under the intercept and quadratic and linear coefficients give their respective contribution in the quadratic regression. Last column gives the overall $P$ value.

\begin{tabular}{|c|c|c|c|c|c|c|}
\hline Host life stage & Coefficient $x^{2}$ & Coefficient $\mathrm{x}$ & Intercept & $\mathrm{df}$ & $\mathrm{F}$ & $P$ \\
\hline \multicolumn{7}{|c|}{ Head width } \\
\hline $1^{\text {st }}$ instar & $\begin{array}{c}6482.5 \\
P=0.829\end{array}$ & $\begin{array}{c}-2619.1 \\
P=0.901\end{array}$ & $\begin{array}{c}326.12 \\
P=0.930\end{array}$ & 2,16 & 5.46 & $P<0.001$ \\
\hline $2^{\text {nd }}$ instar & $\begin{array}{c}63708.0 \\
P=0.002\end{array}$ & $\begin{array}{c}48692.0 \\
P=0.002\end{array}$ & $\begin{array}{l}-9380.70 \\
P=0.002\end{array}$ & 2,21 & 8.71 & $P=0.01$ \\
\hline $3^{\text {rd }}$ instar & $\begin{array}{c}-6245.3 \\
P=0.803\end{array}$ & $\begin{array}{c}7408.4 \\
P=0.695\end{array}$ & $\begin{array}{l}-1621.00 \\
P=0.648\end{array}$ & 2,22 & 11.22 & $P<0.001$ \\
\hline $4^{\text {th }}$ instar & $\begin{array}{c}5967.2 \\
P=0.598\end{array}$ & $\begin{array}{c}-2256.7 \\
P=0.786\end{array}$ & $\begin{array}{c}272.56 \\
P=0.858\end{array}$ & 2,13 & 19.44 & $P<0.001$ \\
\hline Adult & $\begin{array}{l}-51192.0 \\
P=0.007\end{array}$ & $\begin{array}{c}42353.0 \\
P=0.005\end{array}$ & $\begin{array}{l}-8357.60 \\
P=0.006\end{array}$ & 2,16 & 8.97 & $P<0.001$ \\
\hline \multicolumn{7}{|c|}{ Hind tibia length } \\
\hline $1^{\text {st }}$ instar & $\begin{array}{c}8480.8 \\
P=0.103\end{array}$ & $\begin{array}{c}-5610.6 \\
P=0.179\end{array}$ & $\begin{array}{c}1085.60 \\
P=0.198\end{array}$ & 2,16 & 23.31 & $P<0.001$ \\
\hline $2^{\text {nd }}$ instar & $\begin{array}{l}-11001.0 \\
P=0.151\end{array}$ & $\begin{array}{c}10400.0 \\
P=0.122\end{array}$ & $\begin{array}{l}-2152.30 \\
P=0.140\end{array}$ & 2,21 & 6.33 & $P<0.001$ \\
\hline $3^{\text {rd }}$ instar & $\begin{array}{c}-4686.9 \\
P=0.570\end{array}$ & $\begin{array}{c}5569.8 \\
P=0.434\end{array}$ & $\begin{array}{l}-1242.80 \\
P=0.415\end{array}$ & 2,22 & 8.61 & $P<0.001$ \\
\hline $4^{\text {th }}$ instar & $\begin{array}{c}5301.0 \\
P=0.525\end{array}$ & $\begin{array}{c}-2808.9 \\
P=0.325\end{array}$ & $\begin{array}{c}490.56 \\
P=0.589\end{array}$ & 2,13 & 22.29 & $P<0.001$ \\
\hline Adult & $\begin{array}{c}27972.0 \\
P=0.359\end{array}$ & $\begin{array}{l}-23365.0 \\
P=0.387\end{array}$ & $\begin{array}{c}5150.70 \\
P=0.388\end{array}$ & 2,16 & 2.95 & $P=0.08$ \\
\hline
\end{tabular}



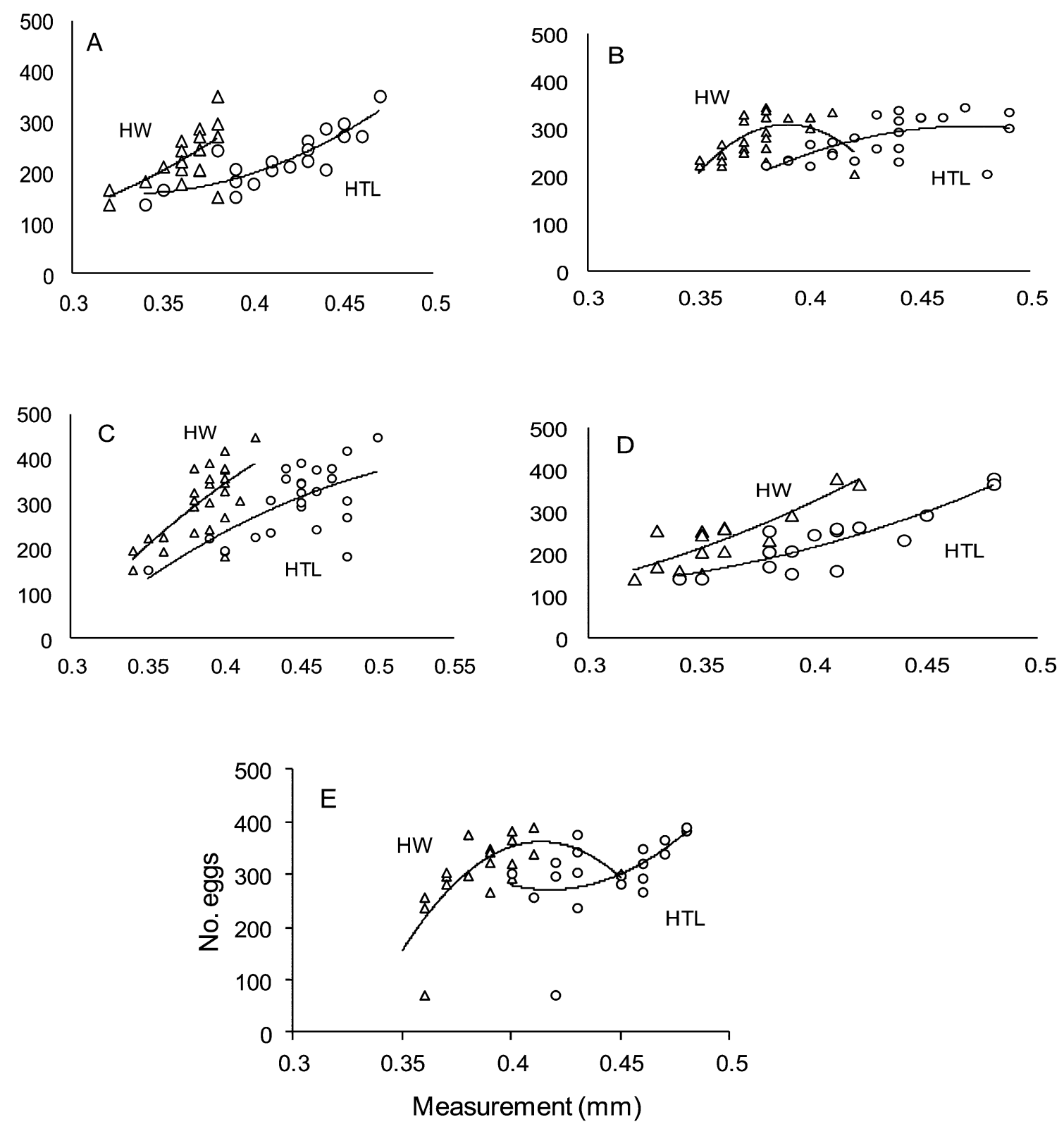

Fig. 4. Quadratic regressions of total egg load of Lysiphlebus fabarum females on head width (HW, triangles) and hind tibia length (HTL, circles) when hosts were parasitized in different life stages (A - first instar; B - second instar; C - third instar; D - fourth instar; E - adult aphid). See Table 3 for line equations.

Direct measurements of body length can be problematic due to issues with abdominal deformation; especially in small species, the natural body shape can change after death (Gauld \& Fitton, 1987). In contrast, sclerotized structures such as the head, leg and even wing, unlike body length, remain relatively invariant over time and thus could provide suitable proxies for body size that can be measured in stored specimens (Blackburn, 1991).

Although wing length was most tightly correlated to total body length among the studied morphometric characteristics, the transparency of the wing margin made accurate measurement of this feature difficult and separation of the wing from the thorax was time consuming. Pronotum width also yielded a good correlation, but the curvature of the pronotum in the anterior marginal area and near the cervix makes this feature difficult to measure as well. Head width had the highest correlation with body length among the traits that were relatively easy to measure. The width of the head often demonstrates a high correlation with other important biological characters of parasitoids such as egg size, egg number, longevity and body mass (van Alphen \& Thunnissen, 1983; O'Neill \& Skinner, 1990; Visser, 1994). In contrast, hind tibia length has been questioned as predictor of parasitoid body mass, for example in Monoctonus paulensis Ashmead (Braconidae) (Nicol \& Mackauer, 1999). Similarly, Pavlik (1993) showed that hind tibia length was not a suitable proxy for quality assessment of Trichogramma species reared on Ephestia kuehniella Zeller.

Host size has a large impact on parasitoid adult size and fitness (Godfray, 1994). Since aphidiinae parasitoids are koinobionts that must grow within their host, their final 
body size is sensitive to the growth stage of the host at the time of parasitism (Gauld, 1988; Li \& Mills, 2004); they may even delay growth and development if they hatch in a very small host (Mackauer \& Kambhampati, 1989). The observed dependence of body size of $L$. fabarum on the growth stage of its host, A. fabae, at the time of parasitism does not follow a monotonic relationship but is unimodal (excluding adult aphids, which cannot be practically employed as a cohort for parasitoid rearing because they are continuously giving birth to first instars). The largest wasps emerged from aphids parasitized in the second and third instars, while those parasitized in the first and fourth instars yielded significantly smaller ones (Fig. 2). Consequently, aphids parasitized in the second and third instar yielded wasps with the largest egg loads (Fig. 3). However, the developmental time of this species in $A$. fabae increases from first instar to adult (Ameri et al., 2012a), suggesting that wasps will have maximal fitness when second-instar nymphs are parasitized. The mechanisms underlying these patterns remain obscure, but likely derive from tradeoffs between a greater ease of overwhelming host defenses in early instars and greater resource availability in later instars of the host (Slansky, 1986; Sequeira \& Mackauer, 1992a, b; Walker \& Hoy, 2003). Thus, aphids in intermediate stages represent a balance of costs and benefits for parasitoid larvae, and aphidiinae wasps reared from second-instar aphids are typically most fit (Hagvar \& Hofsvang, 1986; Kouame \& Mackauer, 1991; Chau \& Mackauer, 2000; Walker \& Hoy, 2003; Xu et al., 2008). Adult aphids may be more suitable hosts than fourth-instar nymphs because their reproductive effort diminishes their resistance to early stage parasitoid development.

The observed egg load of L. fabarum was directly related to body size, as has been demonstrated in other parasitoid species (O’Neill \& Skinner, 1990; Jervis et al., 2001; Bezemer et al., 2005). For example, Sagarra et al. (2001) showed that body size was not only positively correlated with lifetime fecundity in female Anagyrus kamali Moursi, but also with longevity and daily oviposition rate. Thelytokous populations of L. fabarum are moderately proovigenic, as females contain about $60 \%$ of their maximum egg load at emergence (M. Ameri, unpubl. data). Since the longevity of this strain at $21^{\circ} \mathrm{C}$ is about four days (Ameri et al., 2012b), egg load is likely maximal at three days. Thus, females are unlikely to become egg limited even under laboratory conditions.

To conclude, second-instar black bean aphids appear to be the most suitable life stage for the rearing of $L$. fabarum, yielding large offspring with high fecundity and the shortest developmental time. Head width can be used as a proxy of quality control in mass cultures of this wasp.

ACKNOWLEDGEMENTS. We thank Shahid Chamran University of Ahvaz for providing support for this research. We also thank Iranian National Science Foundation (INSF) for financial support.

\section{REFERENCES}

van Alphen J. \& Thunnissen I. 1983: Host selection and sex allocation by Pachycrepoideus vindemiae Rondani (Pteromalidae) as a facultative hyperparasitoid of Asobara tabida Nees (Braconidae; Alysiinae) and Leptopilina heterotoma (Cynipoidea; Eucoilidae). - Neth. J. Zool. 33: 497-514.

Ameri M., Rasekh A., Allahyari H. \& Mahi H. 2012a: Comparison of the adult size and pre-adult developmental time of a thelytokous population of the parasitoid wasp Lysiphlebus fabarum (Marshall) at different host growth stages. In: Proceedings of $20^{\text {th }}$ Iranian Plant Protection Congress, 25-28 August, 2012, Shiraz. p. 13.

Ameri M., Rasekh A. \& Allahyari H. 2012b: An investigation on the effect of host quality and different dietary regimes on longevity of Lysiphlebus fabarum (Marshall), a thelytokous parasitoid of the black bean aphid, Aphis fabae Scopoli. In: Proceedings of $20^{\text {th }}$ Iranian Plant Protection Congress, 25-28 August, 2012, Shiraz. p. 14.

Belshaw R. \& Quicke D.L.J. 2003: The cytogenetics of thelytoky in a predominantly asexual parasitoid wasp with covert sex. - Genome 46: 170-173.

Bezemer T.M., Harvey J.A. \& Mills N.J. 2005: Influence of adult nutrition on the relationship between body size and reproductive parameters in a parasitoid wasp. - Ecol. Entomol. 30: 571-580.

BLACKBURN T. 1991: Evidence for a 'fast-slow' continuum of life-history traits among parasitoid Hymenoptera. - Funct. Ecol. 5: 65-74.

Bourchier R., Smith S. \& Song S. 1993: Host acceptance and parasitoid size as predictors of parasitoid quality for massreared Trichogramma minutum. - Biol. Contr. 3: 135-139.

BRANDL R. \& VidAL S. 1987: Ovipositor length in parasitoids and tentiform leaf mines: adaptations in Eulophids (Hymenoptera: Chalcidoidea). Biol. J. Linn. Soc. 32: 351-355.

Burnham K.P. \& Anderson D.R. 2002: Model Selection and Multimodel Inference: A Practical Information-Theoretic Approach. 2nd ed. Springer, New York, 490 pp.

Calkins C. \& Ashley T. 1989: The impact of poor quality of mass-reared Mediterranean fruit flies on the sterile insect technique used for eradication. - J. Appl. Entomol. 108: 401-408.

Chau A. \& Mackauer M. 2000: Host-instar selection in the aphid parasitoid Monoctonus paulensis (Hymenoptera: Braconidae, Aphidiinae): A preference for small pea aphids. Eur. J. Entomol. 97: 347-354.

GAUld I. \& FitTon M. 1987: Sexual dimorphism in Ichneumonidae: A response to Hurlbutt. - Biol. J. Linn. Soc. 31: 291-300.

GAULD I.D. 1988: Evolutionary patterns of host utilization by ichneumonoid parasitoids (Hymenoptera: Ichneumonidae and Braconidae). - Biol. J. Linn. Soc. 35: 351-377.

Godfray H.C.J. 1994: Parasitoids: Behavioral and Evolutionary Ecology. Princeton University Press, Princeton, NJ, $488 \mathrm{pp}$.

Hagvar E.B. \& Hofsvang T. 1986: Parasitism by Ephedrus cerasicola (Hymenoptera: Aphidiidae) developing in different stages of Myzus persicae (Homoptera: Aphididae). - Entomophaga 31: 337-346.

Harvey J.A. \& Strand M.R. 2002: The developmental strategies of endoparasitoid wasps vary with host feeding ecology. - Ecology 83: 2439-2451.

Harvey J.A. \& Vet L.E.M. 1997: Venturia canescens parasitizing Galleria mellonella and Anagasta kuehniella: Differing suitability of two hosts with highly variable growth potential. -Entomol. Exp. Appl. 84: 93-100. 
Harvey J.A., Harvey I.F. \& Thompson D.J. 1994: Flexible larval growth allows use of a range of host sizes by a parasitoid wasp. Ecology 75: 1420-1428.

Harvey J.A., Kadash K. \& Strand M.R. 2000: Differences in larval feeding behavior correlate with altered developmental strategies in two parasitic wasps: implications for the sizefitness hypothesis. - Oikos 88: 621-629.

HurLbutT B. 1987: Sexual size dimorphism in parasitoid wasps. — Biol. J. Linn. Soc. 30: 63-89.

Jervis M.A., Ellers J. \& Harvey J.A. 2008: Resource acquisition, allocation, and utilization in parasitoid reproductive strategies. - Annu. Rev. Entomol. 53: 361-385.

Jervis M.A., Heimpel G.E., Ferns P.N., Harvey J.A. \& Kidd N.A.C. 2001: Life history strategies in parasitoid wasps: a comparative analysis of 'ovigeny'. - J. Anim. Ecol. 70: $442-458$.

KouAmé K. \& Mackauer M. 1991: Influence of aphid size, age and behaviour on host choice by the parasitoid wasp Ephedrus californicus: a test of host-size models. - Oecologia 88: 197-203.

VAN LENTEREN 2003: Need for quality control of massproduced biological control agents. In van Lenteren J. (ed.): Quality Control and Production of Biological Control Agents: Theory and Testing Procedures. CABI, London, pp. 1-18.

van Lenteren J., Hale A., KlapwiJk J., Van Schelt J. \& SteinBERG S. 2003: Guidelines for quality control of commercially produced natural enemies. In van Lenteren J. (ed.): Quality Control and Production of Biological Control Agents: Theory and Testing Procedures. CABI, London, pp. 278-316.

Li B. \& MilLs N. 2004: The influence of temperature on size as an indicator of host quality for the development of a solitary koinobiont parasitoid. - Entomol. Exp. Appl. 110: 249-256.

Mackaeur M. \& Kambhampati S. 1989: Parasitism of aphid embryos by Aphidius smithi: some effects of extremely small host size. - Entomol. Exp. Appl. 49: 167-173.

Nicol C.M.Y. \& Mackauer M. 1999: The scaling of body size and mass in a host parasitoid association: Influence of host species and stage. - Entomol. Exp. Appl. 90: 83-92.

O’Neill K. \& Skinner S. 1990: Ovarian egg size and number in relation to female size in five species of parasitoid wasps. J. Zool. 220: 115-122.

PAVLIK J. 1993: The size of the female and quality assessment of mass-reared Trichogramma spp. - Entomol. Exp. Appl. 66: 171-177.

PrICE P.W. 1972: Parasitoids utilizing the same host: adaptive nature of differences in the size and form. Ecology 53: 190-195.

Rakhshani E., Talebi A.A., Manzari S., Rezwani A. \& RAKHSHANI H. 2006: An investigation on alfalfa aphids and their parasitoids in different parts of Iran, with a key to the parasitoids (Hemiptera: Aphididae; Hymenoptera: Braconidae: Aphidiinae). - J. Entomol. Soc. Iran 25: 1-14.

Rasekh A., Michaud J.P., Allahyari H. \& Sabahi Q. 2010: The foraging behavior of Lysiphlebus fabarum (Marshall), a thelytokous parasitoid of the black bean aphid in Iran. - J. Insect Behav. 23: 165-179.

Rasekh A., Michaud J.P., Kharazi-Pakdel A., Allahyari H. \& RAKHSHANI E. 2011: Report of a thelytokous population of Lysiphlebus fabarum (Marshall) (Hymenoptera: Aphidiidae) from Iran. - J. Entomol. Soc. Iran 30: 83-84.

Roitberg B.D., Boivin G. \& Vet L.E.M. 2001: Fitness, parasitoids, and biological control: an opinion. - Can. Entomol. 133: 429-38.

Sagarra L.A., Vincent C. \& Stewart R.K. 2001: Body size as an indicator of parasitoid quality in male and female Anagyrus kamali (Hymenoptera: Encyrtidae). - Bull. Entomol. Res. 91: 363-367.

Sampaio M.V., Bueno V.H.P. \& De Conti B.F. 2008: The effect of the quality and size of host aphid species on the biological characteristics of Aphidius colemani (Hymenoptera: Braconidae: Aphidiinae). - Eur. J. Entomol. 105: 489-494.

Sequeira R. \& Mackauer M. 1992a: Covariance of adult size and development time in the parasitoid wasp Aphidius ervi in relation size of its host, Acyrtosiphon pisum. - Evol. Ecol. 6: $34-44$.

Sequeira R. \& Mackauer M. 1992b: Nutritional ecology of an insect host-parasitoid association: the pea aphid-Aphidius ervi system. - Ecology 73: 183-189.

SLANSKY F. JR. 1986: Nutritional ecology of endoparasitic insects and their hosts: an overview. - J. Insect Physiol. 32: 255-261.

SPSS 1998: SPSS 8.0 for Windows. SPSS Inc. Prentice Hall, New Jersey.

Talebi A.A., Rakhshani E., Fathipour Y., Starý P. \& TomaNović Ž. 2009: Aphids and their parasitoids (Hym., Braconidae: Aphidiinae) associated with medicinal plants in Iran. Am.-Euras. J. Sustain. Agric. 3: 205-219.

WALKeR A.M. \& HoY M.A. 2003: Responses of Lipolexis oregmae (Hymenoptera: Aphidiidae) to different instars of Toxoptera citricida (Homoptera: Aphididae). - J. Econ. Entomol. 96: 1685-1692.

Xu Q., Meng L., Li B. \& Mills N. 2008: Influence of host size variation on the development of a koinobiont aphid parasitoid, Lysiphlebus ambiguus Haliday (Braconidae, Hymenoptera). - Bull. Entomol. Res. 98: 389-395.

Received August 12, 2012; revised and accepted March 11, 2013 
